\title{
Contra la Pospolítica: Arqueología de la Guerra Civil Española
}

\author{
Against post-politics: Archaeology of the Spanish Civil War
}

\author{
Alfredo González-Ruibal ${ }^{1}$
}

\begin{abstract}
La arqueología más dificil de practicar en España es la del siglo XX después de Cristo. Franquear la linea que separa lo que no ha sido descubierto y llevarlo al campo de lo registrado no es sólo un logro de la inteligencia. Es la prueba de un carbono moral. Quienes escarnecen esta laboriosa arqueografía de la memoria republicana y de la resistencia contra la tiranía, quienes ignoran el holocausto español, creen hablar desde un futuro inmaculado pero lo hacen desde la vieja garita de la inhumanidad. Manuel Rivas (2007).
\end{abstract}

\section{RESUMEN}

Desde los años 80 del pasado siglo se han incrementado en el discurso arqueológico, especialmente anglosajón, pero también latinoamericano, las referencias a la ética y a la política. Durante la última década, muchos arqueólogos han visto en la multivocalidad el epitome de una arqueología politicamente comprometida. En este artículo se defiende que la preocupación por cuestiones éticas y la multivocalidad se encuentran muy lejos de constituir la base de una arqueología crítica. Son más bien un sintoma del momento pospolitico en que vivimos. En concreto, el triunfo progresivo de la ética sobre la politica en arqueología corrobora este afianzamiento de principios neoliberales en la disciplina. A partir del ejemplo de la arqueología de la Guerra Civil Española y con base en las teorías de Slavoj Žižek, se analizan los problemas de la politica posprocesual. En este caso la ética, el fundamentalismo democrático y diversas formas de multivocalidad se están utilizando por parte de la derecha para neutralizar el potencial verdaderamente critico y radical que la exhumación de los restos del conflicto podría comportar. Se propone, por tanto, una arqueología verdaderamente politica, basada en la exclusión, la división y la intolerancia (sensu Žižek).

Palabras Clave: Arqueología Posprocesual, Ética, Multivocalidad, Guerra Civil Española, Slavoj Žižek.

\begin{abstract}
Since the 1980s archaeological discourse has been increasingly filled with references to ethics and politics. During the last decade, many archaeologists have seen in multivocality the epitome of a politically-compromised archaeology. In this paper, I argue that the concern for ethical issues and multivocality are far from being a sound basis for a critical archaeology. They are rather a symptom of the postpolitic moment in which we are living. In fact, the success of ethics over politics in archaeology corroborates the firm rooting of neoliberal principles in the discipline. Drawing upon the example of the Spanish Civil War and Slavoj Żižek's theories, I explore the flaws of post-processual politics. In the Spanish case, ethics, democratic fundamentalism and different forms of multivocality are being used by the right to neutralize the truly critical and radical power that excavating the remains of the conflict might imply. An authentically political archaeology is proposed here, based on exclusion, division and intolerance (sensu Žižek).
\end{abstract}

Key words: Post-processual Archaeology, Ethics, Multivocality, Spanish Civil War, Slavoj Žižek.

\footnotetext{
Laboratorio de Patrimonio, Consejo Superior de Investigaciones Científicas, Santiago de Compostela, España. Correo-e: alfredo.gonzalez-ruibal@iegps.csic.es.

Recibido: Febrero 2010. Aceptado: Abril 2010.
} 


\section{ArqueOlogía POSPOLÍtTICA: LA SUSPENSIÓN ÉTICA DE LA POLÍTICA}

La década de 1980 y la arqueología posprocesual trajeron el fin de la inocencia política en arqueología. Hoy está casi universalmente admitido que los datos "objetivos" no existen y que la posición política y la subjetividad de los arqueólogos juegan un papel fundamental en sus narraciones sobre el pasado, así como en el uso que del pasado hacen en la actualidad (Shanks y Tilley 1987, Holtorf 2005: 546). La reacción contra el positivismo dio lugar a numerosos trabajos críticos; al abrigo del posprocesualismo florecieron las posturas neomarxistas, la teoría crítica y el feminismo (Fernández 2006). Es necesario recordar que la arqueología latinoamericana se había adelantado una década al mundo anglosajón en sus preocupaciones sociales, sin embargo, en el caso latinoamericano la crítica política se realizó a partir de posiciones positivas basadas en el materialismo histórico (Lumbreras 1974). Mientras tanto, en Espańa, debido a la influencia de la dictadura franquista, la arqueología continuó siendo fundamentalmente apolítica (y ateórica), a excepción de los grupos marxistas que surgieron en las universidades de Barcelona y Jaén durante los ańos 80.

La década de los 90 fue testigo de un cierto relajamiento político, al menos en la academia anglosajona, debido en parte al ascenso de la fenomenología como campo teórico prioritario. A partir de finales de la déca$\mathrm{da}$, volvieron a resurgir las preocupaciones sociales de la mano de la teoría poscolonial y la ética, que cada vez ocupan un lugar más importante en la "agenda" de los arqueólogos. En paralelo a estos desarrollos, se ha ido extendiendo la idea de que existe una multitud de voces e intereses distintos, tanto en el pasado como en el presente, y que el arqueólogo no posee más que una visión entre muchas: su papel es, ante todo, el de mediador (y promotor) de la pluralidad (Gnecco 1999, Hodder 2003).

Este interés por escuchar distintas voces (multivocality) es afín al triunfo del paradigma multicultural en las ciencias sociales y en el régimen neoliberal. Así, en muchos proyectos arqueológicos hoy en día es normal que se defienda el escuchar otras opiniones (más allá de la academia), hacer participar a las comunidades locales, a los aficionados o a los grupos minoritarios o incluso considerar la arqueología como una forma más de acercarse al pasado entre muchas (Holtorf 2005, 2006; Haber 2007, 2009). Una de las mejores muestras de esta práctica reflexiva sería el proyecto de Çatal Höyük, dirigido por Ian Hodder, donde se dejan oír las voces de la comunidad local, los estudiantes que participan en el proyecto, arqueólogos que excavaron el sitio antes y las adoradoras de la diosa madre, entre otros (Hodder 2000). 
Las preguntas que surgen ante este panorama son las siguientes: ison todas las voces iguales? ¿Es necesariamente progresista dejar hablar a todo el mundo? ¿Es la lucha por la liberación simplemente reducible al derecho a narrar (Žižek 2004a: 190), como parece deducirse de algunos trabajos (Haber et al. 2007, Gnecco y Hernández 2008)?

Mi objetivo aquí es demostrar que el supuesto interés por la política de la arqueología anglosajona a partir de los años 80 es mucho más superficial, en términos generales, de lo que se ha hecho creer y que en realidad dicho interés es un síntoma más del ambiente pospolítico que caracteriza a la modernidad tardía. El énfasis en la ética de los últimos años significaría el apogeo de la pospolítica y la neutralización definitiva del auténtico compromiso: el discurso ético, generalmente expresado en clave cultural o social (derechos de las minorías étnicas, sexuales, sociales, etc.), deja en suspensión la política (la crítica a la estructura de orden neoliberal) (cf. en este sentido Hamilakis 2005). En este trabajo trataré de poner en evidencia, con ayuda de Slavoj Žižek y el ejemplo de la Guerra Civil Española, las limitaciones y contradicciones de la despolitización actual de nuestra disciplina.

\section{LA GUERRA CIVIL ESPAÑOLA EN PERSPECTIVA POSPOLÍTICA}

Pese a la gran relevancia que tiene la arqueología de la Guerra Civil y la represión franquista en la sociedad española, la realidad es que el comienzo de estos estudios se ha retrasado mucho con respecto a los del Cono Sur (Bellelli y Tobin 1985), donde, paradójicamente, los gobiernos dictatoriales llegaron a su fin más tarde. Este tardío comienzo de la arqueología de la represión se puede explicar por la larga dictadura de 40 ańos, la magnitud que llegó a alcanzar el exterminio y el peculiar carácter de la transición democrática. Por otro lado, la práctica arqueológica y forense de la represión en España no está generando aún un debate teórico equivalente al de Sudamérica (Carrasco et al. 2004, Funari y Zarankin 2006, Bianchi 2008, Zarankin y Salerno 2008, para España véase Gassiot 2008, Ferrándiz 2009), lo cual puede atribuirse a la naturaleza menos reflexiva de la arqueología y antropología españolas respecto a las de América Latina. Finalmente, mientras en Chile, Argentina y Uruguay (López Mazz 2006) numerosos cargos de la dictadura han sido enjuiciados, en España la única persona procesada en relación con la dictadura franquista ha sido el juez que ha tratado de reabrir la causa de las desapariciones. Aunque con menos repercusión mediática, decenas de historiadores han sido llevados a juicio por investigar hechos represivos cometidos durante la guerra y la dictadura (Espinosa 2009) ${ }^{1}$. El 
caso español, por lo tanto, no se puede poner precisamente como ejemplo a seguir. Sin embargo (o quizá precisamente por ello), creo que la realidad política en la que tiene que manejarse la arqueología de la guerra y la represión en España puede resultar muy ilustrativa de las relaciones entre arqueología y política en general y puede servir de contrapunto comparativo al complejo y variado contexto latinoamericano.

La Guerra Civil Española tuvo lugar entre 1936 y 1939 (cf. una síntesis de la historia militar en Beevor 2006). En 1931 el monarca Alfonso XIII abdicó y se exilió tras unas elecciones municipales que dieron el voto masivamente a los partidos republicanos. Se proclamó entonces la Segunda República Española y seguidamente se redactó una constitución democrática, que garantizaba derechos civiles, como la libertad de expresión y de prensa, el sufragio universal masculino y femenino, la educación pública y laica, el divorcio y el matrimonio civil, etc. (para una síntesis de la República véase Payne 1995). La República se encontró pronto con la reacción implacable de los representantes del Antiguo Régimen: militares, Iglesia y terratenientes, que lucharon por desestabilizar el nuevo sistema político. Cuando en febrero de 1936 las elecciones generales dieron el poder al izquierdista Frente Popular, los planes para derrocar al régimen republicano se aceleraron. El comienzo del conflicto, en julio de 1936, tuvo lugar con el levantamiento de sectores reaccionarios del ejército en la colonia española de Marruecos. Frente a lo que muchos conspiradores esperaban, el gobierno republicano no se derrumbó. Los golpistas tampoco cejaron en su empeño de hacerse con el poder y la guerra se convirtió en un hecho inevitable. Los rebeldes se ganaron las simpatías y la colaboración de las potencias fascistas, Italia y Alemania, mientras que el bando republicano, incapaz de lograr el apoyo de las democracias europeas, temerosas de incomodar a Hitler, sólo consiguió la ayuda de la Unión Soviética. Las disensiones en el bando republicano, que contrastaban con el mando monolítico de los sublevados, unificados bajo el General Francisco Franco, colaboraron en otorgar la victoria a los rebeldes.

Durante la guerra, en uno y otro bando se cometieron atrocidades. En el sector bajo control republicano, se asesinó a cerca de 50.000 personas, mientras que en la zona sublevada se ejecutó al menos a 100.000, a los que hay que añadir otros 50.000 tras el final del conflicto (Juliá 1999, Núñez Díaz-Balart et al. 2009). En la actualidad se manejan cifras de entre 150.000 y 200.000 muertos para el exterminio desencadenado por los militares golpistas. En el caso de la República, buena parte de las muertes ocurrieron de forma irregular, por parte de sectores exaltados, revolucionarios de distintos partidos y delincuentes comunes, mientras que en el otro bando la 
represión formó parte de su estrategia consensuada de terror totalitario (Juliá 1999, Rodrigo 2008). El terror como arma política quedaría de manifiesto claramente en la posguerra: tras la victoria y hasta 1948 las ejecuciones de prisioneros políticos fueron algo habitual. A ello hay que sumar unos 500.000 prisioneros en cárceles y campos de concentración, de los cuales varios miles fallecieron de inanición, torturas o exceso de trabajo (Rodrigo 2005, 2008). Por otro lado, de los cientos de miles de republicanos espańoles que huyeron a Francia, varios miles acabaron en los campos de concentración nazis (especialmente Mauthausen), donde 10.000 perderían la vida antes de su liberación en 1945.

Después de 1948 el número de ejecuciones, encarcelamientos y torturas descendió y la política represiva franquista se fue suavizando, entre otras cosas por la influencia del contexto político internacional tras la derrota del fascismo. Franco murió en 1975 y bajo la dirección del rey impuesto por el dictador, Juan Carlos I, España comenzó su periplo hacia la democracia (Gallego 2008). El hito más importante de este período que se conocería como la Transición fue la proclamación de la Constitución Española, votada en referéndum en 1978. Algunos intentos de recuperar la memoria de los represaliados a fines de los años 70 e inicios de los 80 , con exhumaciones y celebraciones conmemorativas, se vieron interrumpidos bruscamente por el fallido golpe de estado militar del 23 de febrero de 1981 (Silva y Macías 2003: 122). La impresión general es que el país no se encontraba maduro para revisitar la historia reciente y que cualquier tipo de revisión podía llevarnos de nuevo a la guerra civil y a la dictadura. Pese a 14 años de gobierno socialista, la guerra y la represión franquista continuaron bien enterradas. A dicho entierro contribuyó sin duda la Ley de Amnistía promulgada en 1977, una ley de punto final que impide perseguir legalmente cualquier delito político cometido durante el Franquismo. Sobre la base de esta ley se está juzgando actualmente, por prevaricación y a instancias del partido fascista español (Falange), a Baltasar Garzón, el único juez que ha tenido el valor de reabrir la causa de la represión franquista.

Pese a este silencio impuesto, entre fines de los años 90 y principios del nuevo milenio, durante el gobierno derechista del Partido Popular, las voces discordantes con la Transición comenzaron a hacerse oír cada vez más. Entre los críticos más prominentes se encuentra el sociólogo Vicenç Navarro, que fue de los primeros en someter a revisión el proceso de transición democrática en foros públicos (cf. Navarro 2002). La idea de que no se ha hecho justicia a las víctimas de Franco y que nuestra incapacidad para revisar esta injusticia fundamental tiene repercusiones en nuestra situación política en la 
actualidad, se ha ido afianzando en los sectores progresistas. La publicación del libro editado por Juliá (1999) sobre las víctimas del conflicto fue un importante paso. Pero el hecho con más repercusiones fue el recomienzo en el año 2000 de las exhumaciones de represaliados, esta vez de forma científica y promovidas por la Asociación para la Recuperación de la Memoria Histórica - ARMH (Silva y Macías 2003). En el año 2003 empezaron las actividades del Foro por la Memoria, cuyo objetivo es también exhumar e identificar los cadáveres de ejecutados en la represión franquista (Barragán y Castro 2004-2005). Otra iniciativa de esos años ha sido Todos los Nombres, asociación andaluza que pretende recuperar la identidad de todos y cada uno de los asesinados por el franquismo en el sur de Espańa, puesto que todavía no existe un listado completo ${ }^{2}$. No por casualidad es en estos momentos cuando se realizan las primeras excavaciones en trincheras de la Guerra Civil: las primeras tienen lugar en Madrid en 1999 y 2000 (PérezJuez et al. 2002), y en los años siguientes se extienden los trabajos a Cataluña y Aragón (cf. González Ruibal 2007, 2008). Durante los últimos años, los periódicos han publicado continuamente noticias sobre exhumaciones y descubrimientos arqueológicos relacionados con la Guerra Civil (la mayor parte de estos últimos por parte de aficionados). Para 2009 el número de cuerpos recuperados en exhumaciones forenses es de cerca de 5.000. Sólo en la comunidad autónoma de Castilla y León se exhumaron en torno a 700 represaliados entre 2000 y 2008 (Santaolalla y Salinas 2008). El caso más impresionante, sin embargo, es el del cementerio de San Rafael (Málaga), en cuyas fosas comunes se han recuperado 2.840 cadáveres de represaliados durante la Guerra Civil. Entre los muertos se encuentran 40 niños, hijos de republicanos que murieron de hambre o enfermedades, y varias mujeres (Fernández 2009).

El interés popular por la recuperación del pasado se ha reflejado en un sinnúmero de publicaciones sobre la Guerra Civil, que abarrotan las librerías desde el año 2000, en la aparición de asociaciones que visitan y documentan los restos arqueológicos de la guerra (González Ruibal 2007, 2008) y en la reacción de los políticos. Por lo que respecta a esto último, el año 2004, con el regreso al gobierno del Partido Socialista, comenzó a plantearse una ley para la Recuperación de la Memoria Histórica que fue finalmente aprobada en 2007 (con el título Ley por la que se reconocen y amplian derechos y se establecen medidas en favor de quienes padecieron persecución o violencia durante la Guerra Civil y la Dictadura). Los distintos borradores de la ley han sido considerados excesivamente radicales por la derecha, que los rechazó de plano, y demasiado tibios por parte de la izquierda y los nacionalismos, que piden un mayor compromiso político. Al contrario de lo que sucede en 
Argentina, la ley del punto final sigue vigente y con toda probabilidad no será revocada. La controversia que se ha producido en torno a la ley es la misma que afecta a la arqueología: ¿Debemos recuperar el pasado o es mejor olvidarlo? ¿Qué es lo mejor para la democracia? ¿Qué versión del pasado debe predominar?

La arqueología de la Guerra Civil se enfrenta a una tremenda oposición, con frecuencia efectuada de forma sutil o indirecta, por ejemplo, impidiendo cualquier tipo de financiación pública a estos proyectos en zonas controladas por la derecha. Esta oposición proviene, por un lado, de los sectores de la ultraderecha, que se ven ahora apoyados por "historiadores" filofranquistas que acusan a la izquierda de la Guerra Civil y minimizan la represión fascista (vid. crítica en Reig Tapia 1999). Según estos autores, Franco habría impedido el triunfo del comunismo en Espańa y habría, en última instancia, facilitado la democracia y el bienestar económico que ahora disfrutamos. Naturalmente, semejante visión es rebatida, con abrumadoras pruebas documentales, por la mayor parte de los historiadores profesionales. Sin embargo, la literatura revisionista tiene un notable éxito popular.

La oposición a la arqueología de la Guerra Civil proviene de otro lado también: un gran número de españoles que desconocen la historia reciente o poseen sólo nociones tergiversadas por la hagiografía franquista y que consideran que desenterrar el pasado es negativo para la democracia porque reabre viejas heridas. Dentro de este amplio grupo se encuentra tanto gente de derecha (mayoritariamente) como de la izquierda moderada o centroizquierda. En general, predomina la idea de que hay que mirar al futuro, reconocer que en la Guerra Civil no hubo buenos ni malos, sino que fue una guerra fratricida sin sentido donde todos sufrieron mucho y donde todos cometieron atrocidades. La Transición y la Constitución habrían puesto punto final al resentimiento y la confrontación entre españoles, por lo que lo más prudente es no criticar la forma en que España llegó a dotarse de un régimen democrático.

Mis tesis al respecto son las siguientes: 1) que esta visión, que se quiere hacer dominante, es una perspectiva pospolítica heredera directa de la política de silencio impuesta por el fascismo, 2) que un trauma sólo se supera cuando se habla de él, 3) que hablar, discutir y hacer las cosas públicas es lo que caracteriza a una verdadera democracia (González-Ruibal 2007), 4) que la arqueología, que permite el retorno de lo reprimido, nos hace enfrentarnos a nuestros traumas del pasado, hacer justicia a los represaliados y construir una sociedad más democrática, fundada en una memoria de libertad y no 
en el silencio, 5) que disolver un fenómeno colectivo en miles de traumas individuales y privados tergiversa el pasado y neutraliza su potencial político (González-Ruibal 2009).

Lo que sucede actualmente con la arqueología de la Guerra Civil en España es una abdicación de la política. Para desactivar el poder perturbador que posee semejante pasado traumático se recurre a un mecanismo doble: el fundamentalismo democrático y la multivocalidad.

\section{FundAMENTALISMO DEMOCRÁTICO}

El fundamentalismo democrático hace cualquier cambio imposible: no podemos revisitar la Guerra Civil, no podemos criticar la forma en que se llevó a cabo la transición a la democracia, no podemos poner en tela de juicio un sistema monárquico heredado de una dictadura. Cualquiera de tales intentos es tachado de antidemocrático, sesgado, partidista, totalitario e inaceptable. Significa ir contra el consenso democrático, el concepto pospolítico por antonomasia (Mouffe 2005), y de gran éxito en contextos posdictatoriales — sobre su glorificación en Chile (cf. Moulian 2002: 4246)—. La misma retórica se está utilizando actualmente por la derecha para desautorizar las protestas contra el encausamiento del juez Baltasar Garzón por perseguir los crímenes del franquismo. Los portavoces del Partido Popular han acusado de "antidemocráticos" a quienes se manifiestan contra la actuación del Tribunal Supremo (en manos de la derecha). A lo que conducen tales acciones, se piensa, es a la ruptura de la armonía y el diálogo que permitió la llegada de la democracia. La democracia liberal, en España como en el resto del mundo, trata, por todos los medios, de que se olvide lo que se conoce como "paradoja de la fundación" (Dean 2006: 108): la mancha de la violencia antidemocrática previa a la democracia. La violencia predemocrática se suele identificar con un hecho revolucionario que posibilita en última instancia la llegada de la democracia: el ejemplo paradigmático es la Revolución Francesa. En el caso español, la violencia predemocrática es más compleja y actúa a otro nivel; en realidad se trata de una violencia principalmente simbólica (la Transición democrática ${ }^{3}$ ) que niega una violencia real (la Guerra Civil).

El fundamentalismo democrático está estrechamente relacionado con la identidad nacional espańola en la actualidad. Žižek (1993: 202), en su crítica del nacionalismo en el este de Europa, señala que la "Cosa nacional" no es "en última instancia nada, sino la forma en que los sujetos de una determinada comunidad étnica organizan su 'placer' (jouissance) a través 
de mitos nacionales". En el caso de España, durante la dictadura franquista la Cosa nacional se fundamentaba en el mito del imperio, en la idea de España como reserva espiritual (católica) de Occidente y la defensa patriótica contra el Otro - comunista, masón y judío-. Con el advenimiento de la democracia, la Cosa nacional se transmutó y los mitos nacionalcatolicistas fueron desplazados por mitos democráticos fundamentalistas - la Transición y la Constitución- a partir de los cuales se ha reorganizado el "placer" (jouissance) de los espańoles como comunidad nacional. Supuestamente, Transición y Constitución harían tabula rasa del pasado y constituirían un nuevo origen que condena al olvido las injusticias del régimen anterior para crear un nuevo mundo democrático. En teoría, pues, y según este modelo, la mejor herramienta para tratar con la mancha antidemocrática previa a la democracia (en este caso, los crímenes del Franquismo) sería el olvido,sancionado por la Ley de Amnistía de 1977. La mancha, sin embargo, se resiste a desaparecer de nuestra vista.

¿Qué sucede cuando el fundamentalismo democrático se tambalea? Desde finales de los ańos 90 la crítica soterrada a los problemas de la transición democrática ha ido creciendo en importancia y popularidad. Un momento clave fue la reanudación de las exhumaciones de asesinados durante la guerra, en el año 2000 (Silva y Macías 2003). En la actualidad ya no es posible, como sucedía en el período de transición, acallar las voces disidentes en aras del bien común. Es posible que la intentona golpista de 1981 ratificara, con argumentos sólidos, los peligros de reclamar justicia de forma prematura. Ahora bien, en el momento actual no parece razonable aducir el peligro totalitario como justificación para no reexaminar el pasado. Al tiempo que se generalizaban las críticas a la Transición, comenzó un ataque paralelo contra la Constitución, el otro pilar de la democracia espańola. La crítica, que empezó en su momento por parte de sectores nacionalistas vascos y catalanes, se ha extendido a grupos más moderados, que defienden la posibilidad de modificar la carta magna acorde con los nuevos tiempos y las nuevas necesidades políticas,- - entre otras cosas, en lo referente a la organización territorial de España. No es nada de extrańar que la derecha se haya apoderado de ambos símbolos, Transición y Constitución, en su lucha por hacerse con la Cosa nacional (el himno y la bandera se consideran ya patrimonio de la derecha). Como buenos conservadores, han observado que el fundamentalismo democrático es la mejor forma de reducir el horizonte de aspiraciones democráticas, evitar cualquier cambio y despolitizar la sociedad. 
Sin embargo, al ponerse en cuestión los principios en que se basa el fundamentalismo democrático español, Transición y Constitución, y al crecer las exigencias de reexaminar el pasado, la derecha se ve obligada a descubrir nuevos mecanismos que neutralicen la política. Así pues, recurre al segundo de los mecanismos que señalamos, la multivocalidad, hermana de la multiculturalidad.

\section{Multivocalidad}

Este mecanismo actúa en dos sentidos: en primer lugar, reduce los problemas colectivos a problemas individuales, privados, y, en segundo lugar, reclama la equiparación de todas las voces: todos son víctimas y todos son verdugos.

Žižek ilustra el problema de la multiculturalidad con una serie de dibujos animados, producida por Steven Spielberg, sobre dinosaurios. En la serie se enfatiza la diversidad entre los dinosaurios y la necesidad de que haya todo tipo de criaturas en el mundo. Žižek (2005: 56) se pregunta: "¿significa esto también: tipos agradables y brutales, pobres y ricos, víctimas y torturadores?”. Según el filósofo, “cualquier noción de un antagonismo 'vertical' que atraviese el cuerpo social es estrictamente censurada, sustituida por y/o traducida a la sagrada y distinta noción de diferencias 'horizontales' con las que tenemos que aprender a convivir en la medida en que se complementan entre sî" (Žižek 2005: 56). ¿Cómo traducimos en términos políticos la multiculturalidad? Sencillamente, las diferencias políticas se sitúan en un plano horizontal semejante al de las diferencias culturales (Aguilar y Tantaleán 2008: 402, 406). Todas las víctimas son iguales, todas las voces son equiparables. Se habla de una "locura colectiva" que desembocó en guerra civil (Moreno-Nuño 2005: 124). Es lo mismo ser de derechas, de izquierdas, fascista, estalinista, demócrata o simpatizante de la dictadura, anarquista o centrista. Todas son posturas respetables con las que hay que convivir. Todos fueron víctimas (y verdugos) en la Guerra Civil. Al equiparar a todos, no sólo resulta mucho más difícil entender el por qué del conflicto armado en términos históricos, sino que además se ofrece una visión despolitizada, pero nada inocente, de la Guerra Civil.

Estas voces múltiples del pasado tienen su equivalente en múltiples voces del presente. La arqueología de la Guerra Civil la llevan a cabo un sinfín de colectivos descoordinados entre sí y con objetivos muy específcos (González-Ruibal 2007): estudiar los restos de la Batalla del Ebro o los búnkeres de Asturias, restaurar las trincheras del frente de Aragón o con- 
servar y musealizar un refugio antiaéreo en Murcia. Muchas asociaciones y corporaciones municipales se declaran explícitamente apolíticas en su interés por la guerra (como si tal cosa fuera posible). Las únicas asociaciones con objetivos ambiciosos, al menos a escala territorial, son la Asociación para la Recuperación de la Memoria Histórica y el Foro por la Memoria, por eso son también las más criticadas y polémicas. Estas múltiples voces (descendientes de víctimas, historiadores aficionados, entusiastas de lo militar, arqueólogos, políticos y agentes dinamizadores del turismo local) serían vistas como algo positivo por la arqueología posprocesual. Sin embargo, la fragmentación real que supone la multivocalidad no hace sino favorecer la interpretación de la derecha: la Guerra Civil es un asunto individual, de cada uno y cada uno investiga o se dedica a lo que le parece bien. Frente al esfuerzo de la izquierda por lograr que se tenga en consideración la memoria colectiva de la guerra y se construya una narrativa democrática, la derecha insiste en la existencia de infinitas memorias incompatibles. La derecha, pues, hace suya la idea de la posmodernidad: no existe la sociedad, sólo individuos. Y cada individuo tiene su propia voz.

El mensaje resultante es éste: si uno quiere exhumar los restos de su abuelo lo puede hacer de forma privada en tanto que víctima pura de una catástrofe natural de la que nadie es culpable/todos son culpables; se trata de una voz más que añadir a la polifonía de experiencias bélicas. La Guerra Civil Española se convierte, de este modo, en un desastre "humanitario" que se resiste a ser politizado, como sucedió en el caso de la Guerra de Yugoslavia (Žižek 2004: 193-194). En ningún caso, por lo tanto, puede uno exhumar cadáveres de represaliados como un acto de justicia o de reivindicación política de la víctima, eso sería dar al traste con la igualdad horizontal de todas las voces y de todos los actores en el conflicto. De hecho, las simpatías que uno puede granjearse como familiar en búsqueda de un padre o abuelo asesinado, desaparecen en cuanto uno inserta esa búsqueda en una lucha política más amplia. Sucede así lo mismo que en el caso de las intervenciones militares humanitarias que Žižek (2000: 57-58) critica: "el sujeto al que se protege... se identifica desde el comienzo como una víctima impotente de las circunstancias, privada de toda identidad política, reducida al sufrimiento absoluto". Está bien ayudar a los albano-kosovares como víctimas indefensas del monstruo serbio, prosigue Žižek, pero de ningún modo se les permite deshacerse de su indefensión para reafirmarse como seres políticos soberanos e independientes. Así pues, la OTAN pone buen cuidado de que los albanokosovares continúen siendo víctimas (Žižek 2000: 59). En el momento en que la víctima deja de comportarse como tal y contraataca, se transforma "mágicamente" en un "Otro terrorista / fundamentalista / narcotraficante" 
(Žižek 2000: 60); exactamente el mismo proceso de transformación que se advierte en España, donde la víctima de la catástrofe natural que es la guerra se convierte en un rojo sediento de sangre y su excavador en un tipo revanchista, empeñado en reabrir heridas bien cerradas por la Transición. En suma, si la violencia revolucionaria que da lugar a la democracia supone una suspensión política de la ética (Žižek 2004), la despolitización de los conflictos en aras de un supuesto humanitarismo sería la suspensión ética de la política. Precisamente esta maniobra es la que realiza, continuamente, la arqueología posprocesual: la suspensión de la lucha política en aras de la ética y la suspensión de la crítica estructural al sistema por las soluciones individuales, privadas, locales (cf. Aguilar y Tantaleán 2008: 407). Sobre ello volveré más adelante.

Una tercera forma de neutralizar el potencial político de las exhumaciones es mediante su potencial terapéutico. Žižek (2005a: 136) ha criticado la versión New Age del psicoanálisis, según la cual "tras regresar a la escena traumática primigenia y confrontarla, el sujeto debería, bajo la guía del terapeuta, 'reescribir' esta escena, este marco en última instancia fantasmático de su subjetividad, en una narrativa más 'positiva', benigna y productiva”. Según el filósofo, este mecanismo es el que emplean las minorías, cuando se empeñan en reescribir el pasado de una forma más positiva y asertiva. Es el mecanismo, por tanto, que utilizan los bienintencionados arqueólogos y antropólogos poscoloniales que observan el ingenio y la resistencia indígena por doquier. Como critica Graeber (2004: 99), "tienes que demostrar que la gente que estudias... está resistiendo de forma exitosa alguna forma de poder o influencia globalizadora que se les impone desde arriba... que no se deja engañar, ni aplastar ni homogeneizar; al contrario, está apropiándose o reinterpretando creativamente lo que se les echa encima de un modo que sus creadores jamás habrían adivinado". Así, la conquista de la India o del Congo acaba siendo un mero espejismo o una realidad virtual, fabricada para unos conquistadores estúpidos por unos nativos astutos e indoblegables que han seguido creando culturas florecientes.

En el caso de la Guerra Civil, este proceso de reescritura tiene lugar cuando se considera la exhumación y la identificación del cadáver el fin último de la arqueología forense, como si el fallecido hubiera muerto en un accidente y simplemente fuera necesario localizar el cuerpo (González-Ruibal 2009: 105-110) (vale decir que un debate semejante ha tenido lugar en la arqueología forense argentina, ver p.e. Crossland 2000). No quiere esto decir que la arqueología como terapia sea algo negativo, al contrario. Creo que es absolutamente necesario que la arqueología sirva para clausurar traumas 
arrastrados durante décadas, sería absurdo exigir de una viuda nonagenaria o de un hijo septuagenario que se enzarzaran en una lucha política para reclamar la justicia real que se merecen sus parientes. Lo que quiero decir es que la clausura emocional de las familias no tiene que implicar una clausura del horizonte de la lucha política para los arqueólogos y otros agentes sociales. Enterrar a los muertos y reescribir la historia desde un punto de vista más positivo se puede convertir, como en el caso de las minorías, en un neutralizador de la política. Mucho más grave es la estrategia de la derecha, que considera el Franquismo la vía natural e inevitable (aunque dolorosa) hacia la democracia. Se traza así una suerte de síntesis hegeliana donde todo tiene su explicación racional, y en última instancia positiva, si pensamos que el resultado de esta teleología es la democracia y el bienestar económico de la actualidad (Moreno-Nuño 2005: 126). Este tipo de lógica funciona también en Sudamérica (Moulian 2002: 234).

En conclusión, el caso de la Guerra Civil, como la de muchos otros fenómenos del siglo XX, resulta especialmente adecuado para denunciar los fallos de la arqueología política actual: el fundamentalismo democrático y el pluralismo a ultranza lejos de ser emancipadores, pueden convertirse en elementos coercitivos de la práctica verdaderamente comprometida. En mi opinión, el caso de la Guerra Civil demuestra la necesidad de adoptar un nuevo paradigma político en arqueología, por parte de quienes sean partidarios de realizar una praxis auténticamente crítica. Este paradigma aboga por una arqueología política radical, que abandone la inclusión por la división y que acepte plenamente el conflicto frente a la coexistencia pacífica.

\section{De LA MUlTivocalidad a LA DIVISIÓN: ReCUPERAR LA POLÍTICA}

La neutralización de la política se encuentra profundamente arraigada en nuestra práctica arqueológica. Neutralizamos la política incluso cuando creemos que estamos realizando una práctica concienciada, crítica y progresista, al dejar escuchar las voces de todos, al incorporar a todo el mundo a las narraciones sobre el pasado. La multivocalidad ha tenido especial arraigo en la arqueología histórica y contemporánea y la arqueología realizada con comunidades indígenas. Veamos un ejemplo:

La prisión de Robben Island (Sudáfrica), el centro donde fue encarcelado Mandela y otros muchos líderes anti-Apartheid, se ha convertido en la actualidad en un museo, donde los visitantes pueden explorar las instalaciones de este lugar, que fue usado, principalmente con fines represivos, desde el siglo XVII hasta los años 90 del pasado siglo. Según Corsane (2006: 
69), "Robben Island Museum ha tratado de facilitar la polivocalidad (dejar que se escuchen muchas voces, en ocasiones conflictivas) y la participación del visitante en los procesos de creación de significado". La "polivocalidad" consiste, entre otras cosas, en hacer participar en los planes museísticos a "ex prisioneros políticos y a ex guardianes". Esto encaja perfectamente con los postulados multivocales de Hodder (2000: 14), quien asegura que "aunque como arqueólogos y miembros de la sociedad debemos tomar partido, es posible hacerlo de una forma inclusiva y no-confrontacional" (mi cursiva). Por ejemplo, invitando educadamente a un carcelero a que nos hable de sus experiencias durante el Apartheid. De hecho, lo que Hodder entiende por tomar partido es algo bastante particular. Más que mantener una determinada posición, significa navegar en un mar de interpretaciones conflictivas tratando de no contrariar a nadie y satisfacer en la medida de lo posible a todo el mundo, sin que se resientan los objetivos científicos del arqueólogo; se incorpora así a la narración sobre Çatal Höyük a las feministas de los Goddess groups, a los fundamentalistas islámicos locales, a las autoridades turcas y a la empresa de tarjetas de crédito que financia la excavación (Hodder 2000: 11). De este modo, Hodder opina que "los grupos Goddess y otros en ocasiones hacen afirmaciones difíciles de apoyar en la evidencia" y se apresura a matizar "pero reconozco que se pueden hacer contra-afirmaciones" a las propuestas del equipo investigador. Lo mismo sucede con Holtorf (2005). Este autor reconoce que "no todas las narraciones son igualmente válidas o legítimas", pero a continuación añade: "todas las sensibilidades locales deben ser cuidadosamente estudiadas y deben encontrarse soluciones pragmáticas que permitan una coexistencia pacífica" (Holtorf 2005: 549). Lo que emerge de aquí es la figura del arqueólogo como mediador. Esto es, precisamente, un síntoma de la pospolítica predominante. Según Žižek, dentro de los distintos modos que existen para neutralizar el acontecimiento político, "la pospolítica acude al modelo de la negociación empresarial y del compromiso estratégico" (Žižek 2007: 30).

De los escritos de Hodder (1999, 2000, 2003) no se puede deducir si considera que la comunidad local, los grupos Goddess o el gobierno turco poseen una voz más legítima. Lo que a él le interesa es, simplemente, dialogar y mediar entre las partes. De hecho, cuando se refiere a tomar partido, siempre es en cuestiones de detalle: dejar la casa de la excavación pintada de verde islámico pese a peticiones de turcos laicos, dejar que las diosas recen en el yacimiento pero no unirse a sus fiestas, etc. (Hodder 2003: 11-21). No existe una toma de partido estructural, sino episódica y sin consecuencias. En este caso, quizá no tiene por qué haberla. Pero no creo que sea un modelo ideal a seguir: ¿Es lícito navegar entre posturas opuestas en el caso de comunidades 
afro-americanas, indígenas ex colonizados o de represión política? Es necesario señalar que, frente a la distancia simétrica característica del mundo anglosajón y nórdico, las aproximaciones multivocales en América Latina han venido siendo mucho más comprometidas, incluso por parte de aquellos que han partido de presupuestos teóricos afines a los posprocesuales. En última instancia, bajo el concepto de multivocalidad se está defendiendo la voz de los subalternos (Haber et al. 2007; Gnecco y Hernández 2008) de forma más decidida y menos ambivalente que en la academia anglosajona (Hodder 2008). Quizá el concepto multivocal no sea el apropiado para esta empresa que trata de rescatar no muchas voces, sino otras, las de los desposeídos (Funari and Carvalho 2009).

En todo caso, frente a la visión supuestamente ecuánime, pacífica y conciliadora de buena parte de los defensores de la multivocalidad, considero, siguiendo a Žižek, que la auténtica política debe basarse en la división y la exclusión. Para aclarar este punto y que no se considere que hago apología de la dictadura o del maniqueísmo, recordaré el ejemplo manido del Holocausto: nadie pretende escuchar una diversidad de voces dispares sobre el Holocausto ni conseguir que todo el mundo quede razonablemente satisfecho (los rabinos y los skinheads), ni incorporar una variedad de opiniones (de hecho, ciertas opiniones le pueden llevar a uno a la cárcel): ¿Cuál es la opinión del jefe del campo de concentración? ¿Del católico polaco que delata a sus vecinos judíos? ¿De los carceleros de las SS, de los capos, de los neonazis? Si queremos escuchar diversas voces es para reafirmar nuestro rechazo al Holocausto y subrayar que los judíos, los gitanos y las demás víctimas del nazismo, son las que pueden articular "toda la verdad sobre la situación", como dice Žižek (Žižek y Daly 2004: 141-143). Del mismo modo, me parece aberrante que el discurso de los carceleros tenga que escucharse en Robben Island, después de haber sido la única voz que hemos podido oír durante medio siglo de Apartheid, o que los represores franquistas tengan el mismo derecho a hablar que quienes sufrieron sus torturas.

En España cualquiera estaría de acuerdo con la idea de que el único punto de vista válido es el de los judíos o el de los africanos encarcelados. La ley en España, de hecho, castiga la apología del nazismo y del odio racial. Y los partidos nacionalistas vascos que no condenan la violencia terrorista de ETA son repetidamente prohibidos por las instancias judiciales. Pero en España, como ha señalado el periodista Gilles Tremlett (2006), tenemos una peculiar capacidad para sensibilizarnos con las injusticias ajenas y ser bastante ciegos con las nuestras. Mientras en Chile y Argentina abogamos por la persecución de los represores y la reparación a las víctimas, en España 
optamos por la multivocalidad y la simetría ética. Así, en un gesto supuestamente conciliador, durante el día de las Fuerzas Armadas en octubre de 2004 se invitó a presidir el desfile militar a dos antiguos soldados españoles: un miliciano que combatió contra el nazismo en la División Leclerc, la que liberó París en 1944, y un voluntario de la División Azul, el destacamento español que luchó en el frente oriental a las órdenes de Hitler (Ramoneda 2004). Aquí tenemos la suspensión de la política en todo su esplendor, el neoliberalismo en su faceta más hipócrita. La ética de la igualdad horizontal y de los discursos múltiples neutraliza la política de división y exclusión; la división y exclusión que deberían impedir que un soldado que combatió en el ejército nazi en la campaña militar más atroz de la historia pueda compartir palco con un luchador por la libertad y la democracia.

¿Es este pluralismo positivo? ¿No se trata más bien de almibarar el pasado al modo pseudo-psicoanalítico que criticaba Žižek? ¿`No nos lleva a considerar que en la Segunda Guerra Mundial no hubo buenos ni malos, sino que todos fueron víctimas y perpetradores de atrocidades? Esta es la suspensión ética de la política: sólo se juzgan hechos (buenos o malos) a partir de criterios morales. Así, cuando hablamos de la arqueología de la guerra, quizá la más política de todas las arqueologías, lo que nos ofrecen los arqueólogos anglosajones no es política, sino ética —un tipo de ética-. Gilchrist (2003: 5) señala que uno de los objetivos del volumen que coordina sobre arqueología social del conflicto es apuntar "cuestiones éticas sobre la arqueología de la guerra", tales como "recordar a los caídos, evitar la trivialización de las contribuciones al esfuerzo de la guerra, y asegurar un compromiso emocional con el sujeto de estudio" (siguiendo a Schofield 1999: 179). Por supuesto, cuáles son las razones políticas del conflicto, quién es el agresor y quién el agredido, quién el opresor y quién el oprimido (como los dinosaurios de Žižek), es algo que no conviene explorar, no vaya a ser que nos enfrentemos a cuestiones conflictivas, alguien se moleste y se rompa la armonía y el diálogo. Llegamos de este modo a la paradoja de querer hacer arqueología del conflicto sin conflicto (véase, por ejemplo, Schofield 2005 o Cocroft y Thomas 2003). Porque lo que menos quieren los arqueólogos hoy, pese a todos sus discursos supuestamente radicales, es que se les acuse de tomar partido o levantar ampollas. Una arqueología verdaderamente política debe retomar (y reinventar) el concepto de universalidad que es contrario a la multivocalidad indiscriminada.

Naturalmente, tomar partido - tomar partido de verdad, no negociar visiones dispares, como hacen Hodder o Holtorf (que sólo están dispuestos a molestar a sus compañeros de profesión) — no significa ni falsificar la his- 
toria con discursos basados en nuestra propia subjetividad y orientaciones ideológicas, ni negar las atrocidades del lado con el que mantenemos más afinidad política y moral. Así pues, considerar que los judíos pueden articular toda la verdad sobre el Holocausto no impide condenar el bombardeo aliado de Dresde o Hiroshima, y defender que la República era el sistema legítimo de gobierno en España, destruido por el fascismo, no significa que ocultemos las masacres indiscriminadas llevadas a cabo por militantes de izquierda. En este sentido podemos hablar de un pluralismo legítimo: como arqueólogos, debemos recuperar la voz de los que sufren y de los oprimidos y ello no es en modo alguno incompatible con una práctica política bien definida, progresista y emancipadora (al contrario, es perfectamente coherente con ella).

\section{Conclusión: Por una ARQueología POlÍtica}

Se puede considerar que todo esto se aparta demasiado de la praxis diaria de la arqueología o que sólo es aplicable al caso de la arqueología contemporánea, donde se ponen de manifiesto problemas políticos actuales. No creo que sea así. Considero, al contrario, que la arqueología del pasado contemporáneo deja en evidencia la (pos)política que caracteriza, en general, a la arqueología de hoy ¿Es realmente progresista y liberal la multivocalidad? Cualquier práctica que sitúa en un plano horizontal las distintas opiniones está neutralizando la política y cometiendo una injusticia. En el caso más famoso, al que hacía referencia antes, igualar las voces de los grupos Goddess y de la comunidad turca de Çatal Höyük es profundamente injusto para la comunidad turca. Igualar las voces de los manifestantes pacifistas y los militares en las bases nucleares británicas (Schofield y Anderton 2000) es una táctica, en última instancia, de derechas. Darle la misma importancia a las voces de los celtistas New Age y a los campesinos que incorporan en su universo mítico los poblados de la Edad del Hierro en Espańa es un desprecio, casi racista, a una cultura tradicional, que homologamos a las prácticas esotéricas de la burguesía aburrida de nuestra propia cultura. La multivocalidad olvida que las Goddesses, los militares y los neodruidas tienen unos recursos económicos, un poder y una capacidad de hacerse oír de la que carecen los aldeanos turcos, los pacifistas y los campesinos españoles, como el propio Hodder (2003: 21) reconoce. Eso sin contar que la autoridad moral de un pacifista, al menos para quien se declare crítico y políticamente concienciado, es infinitamente superior a la de un representante del complejo militarindustrial. Parece que sólo en el caso del Holocausto, por el carácter único y desmesurado de su barbarie, somos conscientes de que no todas las voces son iguales, de que sólo merece la pena escuchar una voz: la de las víctimas. 
Lo que debemos hacer es extender la política de exclusión y división que funciona en el Holocausto a muchos otros casos: al colonialismo europeo y norteamericano, al Apartheid, a las dictaduras latinoamericanas, a los desposeídos de los guetos urbanos, por poner sólo algunos ejemplos.

Por otro lado, los problemas que denuncia Žižek respecto al concepto de víctima son perfectamente trasladables a la arqueología. A los arqueólogos norteamericanos les agrada que los indígenas (o los afro-americanos) acudan a su yacimiento a contarles historias sobre los antepasados y a dar su visión de los restos (especialmente si tal visión ayuda a interpretar el registro: Hodder 2003: 25-26), pero dejan de caer simpáticos cuando creen, como dice Žižek, que ellos pueden articular toda la verdad sobre ese pasado, como herederos y como individuos desposeídos por la civilización que ahora excava a sus muertos. Es decir, dejan de resultar simpáticos en el momento en que convierten su voz en un discurso político; en el momento en que dejan en evidencia el carácter falsamente democrático y claramente hegemónico del pluralismo defendido por el arqueólogo. Žižek, siguiendo a Rancière, señala que el acontecimiento verdaderamente político sucedió, en el caso de la Grecia antigua, cuando los miembros del demos "no sólo protestaron contra la injusticia que padecían y exigieron ser oídos... sino que ellos, los excluidos, los que no tenían un lugar fijo en el entramado social, se postularon como los representantes, los portavoces, de la sociedad en su conjunto, de la verdadera Universalidad" (Žižek 2007: 25-26). Cuando reconozcamos que no se trata sólo de oír la voz de los afroamericanos, los indígenas, los represaliados políticos, los desposeídos, sino de reconocer que ellos son la voz, entonces se habrá producido un acontecimiento político en arqueología, se habrá producido una subversión real de la hegemonía.

Todas las voces, en conclusión, no son iguales. Los arqueólogos críticos deberían usar su disciplina para defender a los desposeídos, para luchar contra el neoliberalismo y el totalitarismo y para apoyar una política auténticamente democrática. Por supuesto, afirmar que no todas las voces son iguales y que el pluralismo no es necesariamente liberador no resulta nada fácil de vender, ni es políticamente correcto, ni encaja bien en el orden neoliberal / neoconservador que predomina (más o menos camuflado) en el propio mundo académico, especialmente en el mundo anglosajón (Graeber 2004). Frente a la democracia neoliberal que viene guiando a la arqueología en los últimos ańos, propongo volver nuestra mirada a la democracia radical (Mouffe 2005). Ya va siendo hora de denunciar que bajo tanta preocupación ética, lo que late es una neutralización, con graves consecuencias, del auténtico compromiso político progresista y emancipador. 
Agradecimientos: Este artículo fue originalmente una comunicación presentada en la IV Reunión de Teoría Arqueológica en América del Sur (Catamarca, Argentina), dentro de una sesión sobre arqueología y política coordinada por Dante Angelo, a quien agradezco sus comentarios. Quiero agradecer también las útiles sugerencias de tres evaluadores anónimos, que han contribuido a mejorar este artículo.

\section{Notas}

1 El autor de este artículo tiene el dudoso honor de ser el primer arqueólogo español en pasar a la nómina de los perseguidos judicialmente por los herederos del franquismo. Una querella por calumnias fue interpuesta en 2007 por el hijo de un dirigente fascista que cometió diversas atrocidades en Galicia durante la Guerra Civil. Dichas atrocidades fueron dadas a conocer en un libro por el historiador Dionisio Pereira (contra quien se querellaron en primer lugar) y posteriormente yo las recogí en una página web. Tanto Pereira como yo fuimos absueltos. El caso se recoge en Espinosa (2009).

2 http://www.todoslosnombres.org

3 Digo fundamentalmente, porque hubo bastantes muertes y violentas manifestaciones. El número, sin embargo, es muy reducido si se lo compara con la Guerra Civil o la represión franquista.

\section{BiBLIOGRAFÍA}

Aguilar Díaz, M. y Tantaleán, H. 2008. "El Vuelo de Hermes. Una Crítica a la Posmodernidad en Arqueología desde los Andes". Maguare 22: 397-423.

Barragán, D. y Castro, J.L. 2004-2005. "Arqueología de la justicia. Arqueología de las víctimas de la guerra civil española y de la represión franquista". Revista Atlántica Mediterránea de Arqueología Social 7: 149-174.

Beevor, A. 2006. The battle for Spain: The Spanish Civil War 1936-1939. Weidenfeld \& Nicolson, Londres.

Bellelli, C. y Tobin, J. 1985. "Archaeology of the Desaparecidos". Society for American Archaeology Bulletin 14(2): 6-7.

Bianchi, S. (dir.). 2008. Un centro clandestino de la ciudad de Rosario, Argentina: Antropología politica del pasado reciente. Prohistoria, Rosario.

Carrasco, C., Jensen, K., Cáceres, I. 2004. "Arqueología y Derechos Humanos. Aportes desde una ciencia social en la búsqueda de detenidos-desaparecidos". Actas del XVI Congreso de Arqueología Chilena: 665-673. 
Cocroft, W. D. y Thomas, R. J. C. 2003. Cold war. Building for nuclear confrontation 1946-1989. English Heritage, Swindon.

Corsane, G. 2006. "Robben Island: Facing challenges of creating a National Museum in a World Heritage Site". En Re-mapping the field: New approaches in conflict archaeology, editado por J. Schofield, A. Klausmeier y L. Purbrick, pp. 64-71. Westkreuz, Berlin y Bonn.

Crossland, Z. 2000. "Forensic archaeology and the disappeared in Argentina”. Archaeological Dialogues 7(2): 146-159.

Dean, J. 2006. Žižek's politics. Routledge, Nueva York.

Espinosa Maestre, F. 2009. Callar al mensajero: la represión franquista, entre la libertad de información y el derecho al honor. Península, Barcelona.

Fernández, C. 2009. "La lucha contra el olvido". Málaga Hoy. 29/11/09. Disponible en http://www.malagahoy.es/ article/malaga/574846/la/ lucha/contra/olvido.html

Fernández, V.M. 2006. Una arqueología crítica. Crítica, Barcelona.

Ferrándiz, F. 2009. "Fosas comunes, paisajes del terror". Revista de Dialectología y Tradiciones Populares 64(1): 61-94.

Funari, P.P.A. y Carvalho, A.V. 2009. "The uses of archaeology. A plea for diversity”. Archaeological Dialogues 16 (2): 179-181.

Funari, P.P.A. y Zarankin, A. 2006. Arqueología de la represión y la resistencia en América Latina (1960-1980). Encuentro, Catamarca.

Gallego, F. 2008. El mito de la transición. La crisis del franquismo y los origenes de la democracia (1973-1977). Crítica, Barcelona.

Gassiot, E. 2008. "Arqueología de un silencio. Arqueología forense de la Guerra Civil y del Franquismo”. Complutum 19(2): 119-130.

Gilchrist, R. 2003. "Introduction: towards a social archaeology of warfare". World Archaeology 35(1): 1-6.

Gnecco, C. 1999. Multivocalidad histórica: hacia una cartografía postcolonial de la arqueología. Universidad de Los Andes, Bogotá.

Gnecco, C. y Hernández, C. 2008. "History and Its discontents. Stone statues, native histories, and archaeologists". Current Anthropology 49(3): 439-466. 
González-Ruibal, A. 2007. "Making things public. Archaeologies of the Spanish Civil War”. Public Archaeology 6(4): 259-282.

González-Ruibal, A. (ed.). 2008. Arqueología de la Guerra Civil Española. Complutum 18(2). Universidad Complutense de Madrid, Madrid.

González-Ruibal, A. 2009. "Arqueología y memoria histórica". Patrimonio Cultural de España 1: 103-122.

Graeber, D. 2004. Fragments of an anarchist anthropology. Prickly Paradigm, Chicago.

Haber, A. F. 2007. "Reframing social equality within an intercultural archaeology”. World Archaeology 39(2): 281-297.

Haber, A. F. 2009. "Animism, relatedness, life: Post-Western perspectives". Cambridge Archaeological Journal 19(3): 418-430.

Haber, A.F., Mamaní, E. y Roda, L. 2007. "Conversation with Ernestina Mamaní”. Archaeologies 3(3): 308-319.

Hamilakis, Y. 2005. "Whose world and whose archaeology? The colonial present and the return of the political". Archaeologies 1(2): 94-101.

Hodder, I. 1999. The archaeological process. An introduction. Blackwell, Oxford y Malden (MA).

Hodder, I. 2000. "Developing a reflexive method in archaeology". En Towards reflexive method in archaeology: the example of Çatalhöyük, editado por Ian Hodder, pp. 3-14. British Institute of Archaeology at Ankara, Cambridge.

Hodder, I. 2003. Archaeology beyond dialogue. The University of Utah Press, Salt Lake City.

Hodder, I. 2008. "Multivocality and social archaeology". En Evaluating multiple narratives. Beyond nationalist, colonialist, imperialist archaeologies, editado por Junko Habu, Clare Fawcett y John M. Matsunaga, pp. 196-200. Springer, Nueva York.

Holtorf, C. 2005. "Beyond crusades: how (not) to engage with alternative archaeologies". World Archaeology 37(4): 544-551.

Holtorf, C. 2006. From Stonehenge to Las Vegas. Archaeology and popular culture. Left Coast Press, California. 
Juliá, S. (ed.) 1999. Víctimas de la Guerra Civil. Temas de Hoy, Madrid.

López Mazz, J.Ma . 2006. "Una mirada arqueológica a la represión política en Uruguay (1971-1985)". En Arqueología de la represión y la resistencia en América Latina (1960-1980), editado por P.P.A. Funari y A. Zarankin, pp: 159-182. Encuentro, Catamarca.

Lumbreras, L. 1974. La Arqueología como ciencia social. Ediciones Histar, Lima.

Moreno-Nuño, C. 2005. "The ghosts of Javier Marías. The traumas of a Civil War unforgotten”. En Traces of contamination. Unearthing the Francoist legacy in contemporary Spanish discourse, editado por E.E. Merino y H. Rosi Song, pp: 124-146. Bucknell University Press, Lewisburg.

Mouffe, C. 2005. On the political. Routledge, Oxford, Nueva York.

Moulian, T. 2002. Chile actual: anatomía de un mito. LOM, Santiago de Chile.

Navarro, V. 2002. Bienestar insuficiente, democracia incompleta. Sobre lo que no se habla en nuestro pais. Anagrama, Madrid.

Núñez Díaz-Balart, M., Álvaro Dueñas, Espinosa Maestre, F., García Márquez, J.Ma. 2009. La gran represión. Los años de plomo del franquismo. Flor del Viento, Madrid.

Payne, S. 1995. La primera democracia española. La Segunda República, 1931-1936. Paidós, Barcelona.

Pérez-Juez, A., Morín, J., Barroso, R. y Escolà, M. 2002. "Arqueología de la Guerra Civil: Excavaciones arqueológicas en las trincheras". Revista de Arqueología 250: 22-31.

Ramoneda, J. 2004. "Poco más que un desfile". El País, 14 de octubre de 2004.

Reig Tapia, A. 1999. Memoria de la Guerra Civil. Los mitos de la tribu. Alianza, Madrid.

Rivas, M. 2007. Los libros. El País, 14 de abril de 2007.

Rodrigo, J. 2005. Cautivos: campos de concentración en la España franquista, 1936-1947. Crítica, Barcelona. 
Rodrigo, J. 2008. Hasta la raiz: violencia durante la Guerra Civil y la dictadura franquista. Alianza, Madrid.

Santaolalla, R. e I. Salinas. 2008. "690 cuerpos de represaliados han sido exhumados de 70 fosas desde el 2000". El Norte de Castilla 03/08/08. Disponible en http://www.nortecastilla.es/20080803/local/ valladolid/ cuerpos-represaliados-sido-exhumados-200808031106. html

Schofield, J. 1999. "Conserving recent military remains: choices and challenges for the twenty-first century". En Managing historic sites and buildings, editado por G. Chitty y D. Baker, pp. 173-86. Routledge, Londres.

Schofield, J. 2005. Combat archaeology: material culture and modern conflict. Duckworth, Londres.

Schofield, J. y Anderton, M. 2000. "The queer archaeology of Green Gate: interpreting contested space at Greenham Common Airbase”. World Archaeology 32(2): 236-251.

Shanks, M. y Tilley, C. 1987. Re-constructing archaeology: Theory and practice. Cambridge University Press, Cambridge.

Silva, E. y Macías, S. 2003. Las fosas de Franco: los republicanos que el dictador dejó en las cunetas. Temas de Hoy, Madrid.

Tremlett, G. 2006. Ghosts of Spain. Travels through a country hidden past. Faber \& Faber, Londres.

Zarankin, A. y Salerno, M. 2008 "Después de la Tormenta. Arqueología de la Represión en América Latina". Complutum 19(2): 21-32.

Žižek, S. 1993. Tarrying with the negative. Duke University Press, Durham (NC).

Žižek, S. 2000. The fragile Absolute. Verso, Nueva York.

Žižek, S. 2004. La suspensión politica de la ética. Fondo de Cultura Económica, México D.F.

Žižek, S. 2004a. Organs without bodies. Deleuze and consequences. Routledge, Londres y Nueva York.

Žižek, S. 2005. Bienvenidos al desierto de lo Real. Akal, Madrid. 
Žižek, S. 2005a. "Neighbors and other monsters: a plea for ethical violence". En The Neighbor. Three inquiries in Political Theology de S. Žižek, editado por E.L. Santner y K. Reinhard, pp. 134-190. The University of Chicago Press, Chicago.

Žižek, S. 2007. En defensa de la intolerancia. Sequitur, Buenos Aires, Ciudad de México, Madrid.

Žižek, S. y Daly, G. 2003: Conversations with Žižek. Cambridge, Polity Press. 